\title{
Trampoline injuries in the world and in Turkey
}

\author{
Nurdan Paker \\ Department of Physical Medicine and Rehabilitation, Istanbul Physical Therapy Rehabilitation Training and Research Hospital, Istanbul, Turkey
}

Received: January 2017 Accepted: February 2017

\begin{abstract}
Trampoline continues to be an activity that individuals in every age, but particularly children, enjoy to do for nearly a hundred years. However, it has some unpleasant effects due to the risk of injury. Safety rules, therefore, need to be followed during trampoline activities. Contemporarily, it is not recommended for small children and purposes other that sportive activities in Western countries. In this review, we discuss the trampoline-related injuries to increase the awareness in the society and to shape the regulations related with the trampoline use in Turkey.
\end{abstract}

Keywords: Recreation; safety; sports; trampoline injuries.

Trampoline was first used in early 1930 s by an acrobat in his home for turning somersaults and sportive activities. ${ }^{[1]}$ It was used for sportive activities initially; however, it was, then, utilized in educations of military and aviation areas. In the following years, trampolines were started to be used for entertainment, and even the individuals purchased them for home.

Trampolines have various types. Classical trampolines and soft-edged trampolines have different features. Classical trampolines have a frame made up from steel and springs (Figure 1). Springs serve for a jumping mat to attach to the frame and extend through the jumping surface (Figure 2). Some of the classical trampolines have surrounding protective network. The ones with a soft edge have a flexible jumping surface and there is no need for an additional pad. These are surrounded with a protective network. There is a small surface in mini trampolines. In paired mini trampolines, there are two small jumping surfaces with septa and synchronized activities such as horizontal somersault run are exhibited. Also, there are large rivalry surfaced trampolines. Nowadays, there are trampoline parks organized in wide areas designed as adjacent and seperated with a septum composed of multiple jumping surfaces.
Towards the end of 1990s and 2000s, in countries such as United States (US), Australia, and New Zealand, the number of trampolines has been quickly increased, particularly in houses. As trampoline use becomes widespread in Western countries, trampoline-induced injuries have appeared over time. Since trampoline injuries are ever-increasing, it becomes comparable with bicycle and other sportive injuries. In a declaration published in late 1970s by the American Academy of Pediatrics, trampolines were recommended in schools for physical development of the children, while a second report was published in early 1980s stating that controlled use in schools was suggested, and the use at homes was not advised. ${ }^{[2,3]}$

In a report published in 1999 by the American Academy of Pediatrics, it was strictly recommended the disuse of trampolines in houses and physical education classes in schools and parks. ${ }^{[4]}$ However, widespread use of trampolines was unable to be inhibited. The report published by American Academy of Pediatrics in 1999 was updated in 2007. ${ }^{[5]}$

\section{Risk factors for trampoline injuries}

The majority of the injuries occur during the activities in trampolines exist at home. ${ }^{[6-18]}$ Trampoline injuries are more common in children under six years 


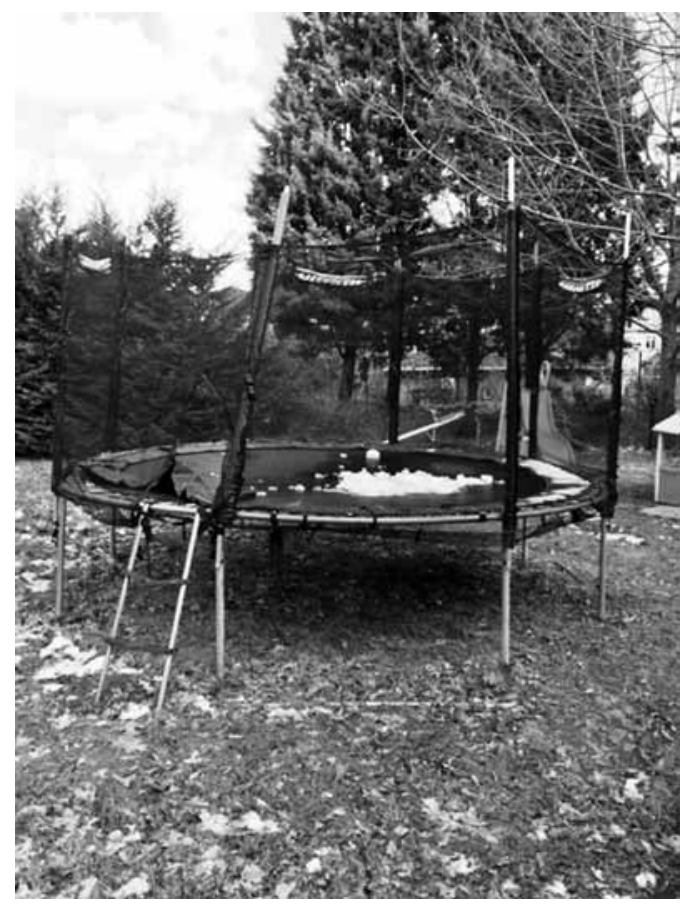

Figure 1. Classical trampoline.

of age, ${ }^{[19]}$ as this age group of children cannot control their jumps. ${ }^{[20]}$ Besides, the risk of injury is higher in the activities performed without the supervision of the parents. Indeed, trampoline activities should be done after the education on trampoline artistries and, preferably, under the supervision of educated supervisors. ${ }^{[1]}$ The injury risk increases, when the activities are performed with more than one person at the same time. ${ }^{[8,11-14]}$ If there is more than one person in trampoline, the risk for injury is the highest for the thinnest one. ${ }^{[11]}$

\section{Trampoline injuries}

During trampoline activities, injuries such as abrasion, contusion, laceration, sprain, dislocation, and fracture may occur in various sites of the body. ${ }^{[6,17,22,23]}$ The most common types of injuries are fractures (36\%), injury to ligaments (36\%), contusions (20\%), lacerations (7\%), and dislocations (1\%). ${ }^{[23]}$ It is also claimed that the $90 \%$ of the injuries occur in private trampolines at home, less than $10 \%$ happen due to trampolines in kindergartens, schools, or gymnastic saloons. ${ }^{[9]}$ It has been reported that trampoline injuries take place at home are head trauma and upper extremity injuries predominantly, whereas lower extremity fractures are more common at park activities. ${ }^{[2]}$ Trampoline injuries usually take place in the summer season. ${ }^{[24,25]}$

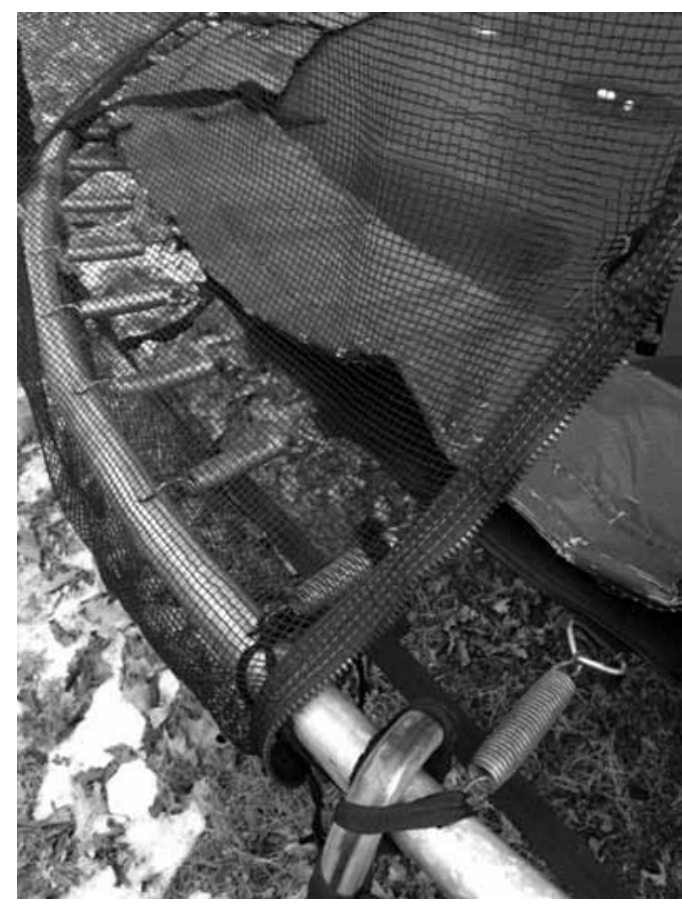

Figure 2. Springs of trampoline.

\section{Causes of injury}

Trampoline injuries frequently occur due to falling to firm ground or hitting the frame or springs of the trampoline ${ }^{[9-11,17]}$ In a study performed by Sandler et al., ${ }^{[9]}$ it was reported that the $67.1 \%$ of injuries were secondary to falls to the ground, $34 \%$ were due to the fall of the mat of the trampoline, and $8.9 \%$ were due to the strikes of the frame or springs of the trampoline.

In another study, it was shown that $19 \%$ of injuries were due to falls from the trampoline and $19 \%$ were due to the strikes to the frame or springs of the trampoline. ${ }^{[26]}$ There are also studies reporting that approximately half of the trampolines lacked the security network. ${ }^{[1,26]}$

\section{Age and trampoline-related injuries}

Trampoline injuries may seen in all ages, but they are more frequent in children. ${ }^{[1,18,26-29]}$ Sandler et al. ${ }^{[9]}$ investigated pediatric trauma database and concluded that 383 children had trampoline injury between 1999 and 2008, and 70\% of this injuries happened to school age children with the ages 5 to 14 . In a study conducted with the data of 556 patients admitted to a university hospital due to trampoline injury between 2001 and 2004 in Norway, it was reported that 53\% of the individuals injured were between the ages of 1 to $10 .{ }^{[23]}$ 


\section{Sex ratio}

The exposure ratio to injuries of female and male children are almost similar. ${ }^{[8,20,25,30]}$

\section{Unauthorized use and the activities performed without any observation}

A previous study reported that $2 \%$ of the injuries are due to the uninformed access to trampoline. ${ }^{[26]}$ It was reported that half of the cases occurred under supervision during injury. ${ }^{[1]]}$

\section{The activities done by more than one person at the same time}

When the activities done on the trampoline by more than one person at the same time, the risk of getting injured increases. ${ }^{[9,11,26,31-33]}$ In particular, between ages 0 to 4 , injuries are seen due to the presence of multiple individuals at the same trampoline. ${ }^{[31]}$ In a study, it was reported that $10.7 \%$ of the injuries occurred precisely when jumping with others. ${ }^{[9]}$ When the trampoline was used by multiple individuals at the same time, the thinnest individual became injured and the lightest individual was found to be 13.6 folds vulnerable to injuries, compared to those with higher bodyweights. ${ }^{[1]}$ The kinetic energy that the heavier individual creates is also higher, and this energy creates more propellent power on the thinnest is to be thought as the reason.

\section{Number of trampoline-related injuries in various countries}

In a study performed by Linakis et al. ${ }^{[14]}$ based on emergency service medical records between 2000 and 2005, it was reported that in ages between 0 and $18,88,563$ individuals were admitted per year due to trampoline-related non-fatal injuries. Between 1990 and 1995, the total number was 41,600. In another study performed by the collection of the data from the National Electronic Injury Surveillance System (NEISS) between 2010 and 2014, there was no significant difference in the number of at home-based trampoline injuries, while the number of at park-based trampoline injuries increased. ${ }^{[22]}$

In addition, it has been reported that more than 13,000 trampoline injuries occur annually in the United Kingdom (UK). ${ }^{[20]}$ In another study conducted in Australia, the number of yearly average injury was 1,737 in 2012 and consecutive 10 years. ${ }^{[34]}$ These data indicate that, despite the safety standards in Australia and security networks in trampolines, the injuries persist.

\section{Trampoline injuries in Turkey}

Trampolines are present in houses, some schools, and recreation centers in Turkey and mostly draw the attention of children. Besides, there is a trampoline park in Turkey. Trampoline, an activity loved by children, is an Olympic sport since 2000. There is a trampoline team in Turkey affiliated with gymnastics federation.

Although children enjoy trampolines very much, there is no report in the literature survey related with the number of trampoline injuries in our country. Only a child who had subdural hematoma due to head trauma and an adult male with tetraplegia after a cervical trauma during the trampoline activities were reported from Turkey. ${ }^{[35,36]}$

There are also instructions in Turkish for the use of trampolines which are prepared by the manufacturers on websites for the safety issues related with the trampoline use.

\section{Injury forms according to age}

Between ages 0 to 4 , injuries such as fracture and dislocation are predominant, while soft tissue injuries are more common between 5 and 18 age group. ${ }^{[14]}$ Fractures related to trampoline parks are more common in young children. In a previous study, it was reported that approximately half of the fractures in trampoline parks develop in children younger than six years of age, and $33.5 \%$ occur in ages between 6 and $1 .^{[22]}$

\section{Injury sites}

Trampoline injuries may occur in various features. Head-neck and trunk injuries, upper and lower extremity injuries, and fractures may be seen. .11,26,27,30] $^{2}$ In a study carried out in the US based on the data between 2010 and 2014, 57\% of injuries in trampoline parks were strains, contusions, and abrasions of the chest and trunk, 63\% were laceration and concussion of the head, $92 \%$ were strains and fractures of the neck, $85 \%$ were strains and fractures of the upper extremity, and $81 \%$ were strains, sprains, and fractures of the lower extremity. ${ }^{[22]}$

\section{Head and neck injuries}

In general, they are serious injuries. ${ }^{[18]}$ In addition to falls from trampoline, strikes to the frame or springs may cause traumatic brain injury, contusion and laceration. ${ }^{[14,26]}$ Soft tissue trauma of the neck and vertebral fractures may also occur. ${ }^{[11,14,18,19]}$ Paraplegia and tetraplegia may develop as a result of vertebral fractures in some cases. Head and neck injury ratios are 20 to $25 \%$ in various series. ${ }^{[7,14,17]}$ A child with 
subdural hematoma due to head trauma was reported previously. ${ }^{[35]}$

\section{Upper extremity injuries}

Upper extremity injuries are also common during trampoline activities. ${ }^{[9,10,13,14,17]}$ A previous study demonstrated that $64 \%$ of the injuries are seen in the upper extremities. ${ }^{[9]}$ Fractures and dislocations are frequent in upper extremities. ${ }^{[14]}$

\section{Lower extremity injuries}

Soft tissue injuries and strains are common in lower extremities. ${ }^{[14,17,25,33]}$ Ankle injuries may occur due to the inversion movement of the ankle.

\section{Fractures}

In particular, fractures of the upper extremities are frequent in trampoline-related injuries. ${ }^{[10,11,24,29]}$ Lower extremity fractures may also occur. ${ }^{[25]}$ Distal radius, ulna, and humerus fractures may be present with tibia fractures. ${ }^{[13,24]}$

It has been reported that trampoline-related lower extremity fractures are due to the presence of more than one person at the same time on the same trampoline. ${ }^{[32,37]}$ In addition, if the growth plate on medial malleolus is affected, the growth may be ceased. ${ }^{[37]}$ Fractures usually occur secondary to falls from the trampoline. ${ }^{[26,34]}$ Trampoline-related proximal tibial metaphysis fractures are usually due to the presence of more than one child at the same time on the same trampoline, eventually the youngest child mostly becomes injured. In general, proximal tibial metaphysis fractures lead to valgus deformity in future. However, this situation is not always valid for trampoline-related fractures. ${ }^{[38]}$ In a study performed by Hurson et al., ${ }^{[1]}$ it was reported that more than half of the trampoline injuries led to fractures. Magnetic resonance imaging is useful for the diagnosis of fractures which are unable to be shown in the plain X-rays in painful situations due to trampoline injuries. ${ }^{[33]}$

\section{The relationship between the type of the trampoline and injury}

Shields et al. ${ }^{[16]}$ screened the data from the NEISS between 1990 and 2002 in the US and compared the injuries due to mini trampoline and classical trampolines. In the aforementioned study, no significant difference was found between mini trampoline and classical trampoline injuries ( 82 vs $91 \%$, respectively). In mini trampoline injuries, lacerations of the head region were common in children under six years; however, between the ages of 6 to 17, lower extremity sprains and strains were more frequent for both trampoline types.

\section{Safety in trampolines with soft edge}

Due to the reason that trampoline-related injuries are remarkable, some studies were performed in Australia to determine whether there were safer trampolines. ${ }^{[31,39,40]}$ Classical trampoline and soft-edged trampoline-related injuries were compared. In softedged trampolines, there was no any injury reported due to falls and hits to hard pieces. ${ }^{[31]}$ Besides, in softedged trampolines, overall injuries were $30 \%$ less and severe injury ratios were lower. ${ }^{[40]}$

\section{Safety issue in trampoline activities}

The increasing number of trampoline-related injuries in the late 1990s in the US made the safety issue a current topic. Suppliers also have some recommendations concerning trampoline-related safety precautions. The usage period of the trampolines sold in 1990s were proclaimed as 10 years; however, the life span of the ones sold in 2000s was set as five years for an increased safety. Trampolines have frames, mats, connection sites of the mats, and surrounding networks. It is not surprising that every part would have a different wear-out time. The frame and the mat are more durable than surrounding safety network and adjacent connection site. Tears may occur in safety network. To prevent injuries due to falls from the teared parts, old and damaged materials need to be changed rapidly.

The US Consumer Product Safety Commission also published a warning on the trampoline use. ${ }^{[6]}$ According to this statement, the topics to pay attention to prevent trampoline-related injuries are the following:

1. Placing the trampoline apart from other play fields,

2. Covering the environment of the trampoline with soft, shock absorbing material,

3. Covering the frame and springs of the trampoline with protective pads,

4. Using the trampoline by one person at one time,

5. Not to do cartwheels on trampoline,

6. Removing the ladders in order to prevent the small children to climb the trampoline,

7. Providing observation to children during trampoline activities,

8. Inhibiting any unauthorized access to the area where trampoline is placed are recommended. ${ }^{[6]}$ 
According to the American Academy of Orthopaedic Surgeons (AAOS), proper precautions must be taken needed, when trampoline is used for sportive purposes: ${ }^{[8]}$

1. Using protective materials during risky movements and cartwheels,

2. Ensuring that trampoline jumping surface is at ground level,

3. Continuously monitoring the safety situation,

4. Replacing the destroyed materials,

5. Prohibiting the use of the trampoline for the children smaller than age of six,

6. Removing the ladders after using the trampoline in order to prevent the small children to climb the trampoline have been declared.

Besides, it is not safe to jump from the trampoline to the ground to exit. ${ }^{[21]}$

In conclusion, trampoline activities may lead to mild or severe injuries on head and neck regions, trunk and extremities. It has been proposed that there is a need to raise the awareness of the society for the probable dangerous outcomes. ${ }^{[1]}$ Woodward et al. $^{[30]}$ recommended the physicians to warn the families for the dangers about trampoline. Currently, in Western countries, the use of trampoline for fun is found inconvenient and recommended only for sportive purposes. ${ }^{[16]}$ In the light of literature data, since children who are younger than age of six are vulnerable injuries particularly, access to trampoline should be inhibited. The presence of only one person at the trampoline and taking the safety precautions decrease the risk of injury. Similar protective precautions must be taken to prevent the injuries in trampoline parks. Risky activities such as turning somersaults and contact of the individuals on the trampoline must not be allowed. ${ }^{[22]}$ There is also a need for fundamental regulations to prevent trampoline induced injuries. Therefore, we need to raise the awareness of the safety issues and risks related with the trampolines in our country. Furthermore, developing relevant regulations on this issue would be useful to prevent trampoline-related injuries.

\section{Declaration of conflicting interests}

The authors declared no conflicts of interest with respect to the authorship and/or publication of this article.

\section{Funding}

The authors received no financial support for the research and/or authorship of this article.

\section{REFERENCES}

1. Walker R. The history of trampolining. Available at: http:// www.jumpsport.com. [Accessed: December 15, 2016]

2. American Academy of Pediatrics. Committee on. Accident and Poison Prevention. Trampolines. News Comment 1977;28:5.

3. American Academy of Pediatrics, Committee on Accident and Poison Prevention. Trampolines. Pediatrics 1981;67:438-9.

4. Trampolines at home, school, and recreational centers. American Academy of Pediatrics. Committee on Injury and Poison Prevention and Committee on Sports Medicine and Fitness. Pediatrics 1999;103:1053-6.

5. Council on Sports Medicine and Fitness, American Academy of Pediatrics., Briskin S, LaBotz M. Trampoline safety in childhood and adolescence. Pediatrics 2012;130:774-9.

6. Trampoline safety alert: Consumer Product Safety Commission Document. Available at: http://www.cpsc.gov/ cpscpub/ pubs/085.html7. [Accessed: December 15, 2016]

7. Smith GA. Injuries to children in the United States related to trampolines, 1990-1995: a national epidemic. Pediatrics 1998;101:406-12.

8. Trampolines and Trampoline Safety Document \#1135. American Academy of Orthopaedic Surgeons. Available at: http://www.aaos.org/wordhtml.papers/position/trampoli. htm. [Accessed: December 15, 2016]

9. Sandler G, Nguyen L, Lam L, Manglick MP, Soundappan SS, Holland AJ. Trampoline trauma in children: is it preventable? Pediatr Emerg Care 2011;27:1052-6.

10. Chalmers DJ, Hume PA, Wilson BD. Trampolines in New Zealand: a decade of injuries. Br J Sports Med 1994;28:234-8.

11. Hurson C, Browne K, Callender O, O’Donnell T, O'Neill A, Moore DP, et al. Pediatric trampoline injuries. J Pediatr Orthop 2007;27:729-32.

12. Esposito PW. Trampoline injuries. Clin Orthop Relat Res 2003;409:43-52.

13. McDermott C, Quinlan JF, Kelly IP. Trampoline injuries in children. J Bone Joint Surg [Br] 2006;88:796-8.

14. Linakis JG, Mello MJ, Machan J, Amanullah S, Palmisciano LM. Emergency department visits for pediatric trampoline-related injuries: an update. Acad Emerg Med 2007;14:539-44.

15. Hume PA, Chalmers DJ, Wilson BD. Trampoline injury in New Zealand: emergency care. Br J Sports Med 1996;30:327-30.

16. Shields BJ, Fernandez SA, Smith GA. Comparison of minitrampoline- and full-sized trampoline-related injuries in the United States, 1990-2002. Pediatrics 2005;116:96-103.

17. Smith GA, Shields BJ. Trampoline-related injuries to children. Arch Pediatr Adolesc Med 1998;152:694-9.

18. Leonard H, Joffe AR. Children presenting to a Canadian hospital with trampoline-related cervical spine injuries. Paediatr Child Health 2009;14:84-8.

19. Furnival RA, Street KA, Schunk JE. Too many pediatric trampoline injuries. Pediatrics 1999;103:57.

20. Paul SP, Barnden J, Kane M. Garden hazards: trampoline injuries. Br J Nurs 2016;25:975. 
21. Royal Society for the Prevention of Accidents (RoSPA) (2015) Garden trampolining. Available at: http://www. rospa.com/rospaweb/docs/garden-trampolining. [Accessed: December 15, 2016]

22. Kasmire KE, Rogers SC, Sturm JJ. Trampoline Park and Home Trampoline Injuries. Pediatrics 2016;138.

23. Nysted M, Drogset JO. Trampoline injuries. Br J Sports Med 2006;40:984-7.

24. Yule MS, Krishna S, Rahiri JL, Hill AG. Trampolineassociated injuries are more common in children in spring. N Z Med J 2016;129:37-43.

25. Shankar A, Williams K, Ryan M. Trampoline-related injury in children. Pediatr Emerg Care 2006;22:644-6.

26. Alexander K, Eager D, Scarrott C, Sushinsky G. Effectiveness of pads and enclosures as safety interventions on consumer trampolines. Inj Prev 2010;16:185-9.

27. Eberl R, Schalamon J, Singer G, Huber SS, Spitzer P, Höllwarth ME. Trampoline-related injuries in childhood. Eur J Pediatr 2009;168:1171-4.

28. Larson BJ, Davis JW. Trampoline-related injuries. J Bone Joint Surg [Am] 1995;77:1174-8.

29. Loder RT, Schultz W, Sabatino M. Fractures from trampolines: results from a national database, 2002 to 2011. J Pediatr Orthop 2014;34:683-90.

30. Woodward GA, Furnival R, Schunk JE. Trampolines revisited: a review of 114 pediatric recreational trampoline injuries. Pediatrics 1992;89:849-54.

31. Eager D, Scarrott C, Nixon J, Alexander K. Survey of injury sources for a trampoline with equipment hazards designed out. J Paediatr Child Health 2012;48:577-81.
32. Blumetti FC, Gauthier L, Moroz PJ. The 'trampoline ankle': severe medial malleolar physeal injuries in children and adolescents secondary to multioccupant use of trampolines. J Pediatr Orthop B 2016;25:133-7.

33. Hauth E, Jaeger H, Luckey P, Beer M. MR imaging for detection of trampoline injuries in children. BMC Pediatr 2017;17:27.

34. Ashby K, Pointer S, Eager D, Day L. Australian trampoline injury patterns and trends. Aust $\mathrm{N} \mathrm{Z} \mathrm{J} \mathrm{Public} \mathrm{Health}$ 2015;39:491-4.

35. Guzel A, Paksu MS, Suna F, Sisman B, Genc E, Dagcinar A, et al. A Dangerous Game; Trampoline and Subdural Hematoma in a Child: Case Report. Turkiye Klinikleri J Pediatr 2013;22:83-5.

36. Ferhatosmanoğlu A, Caf N, Buğdaycı D, Paker N. Trampolin yaralanmasına bağlı tetrapleji. İst FTR 2017;2:40-3.

37. Klimek PM, Juen D, Stranzinger E, Wolf R, Slongo T. Trampoline related injuries in children: risk factors and radiographic findings. World J Pediatr 2013;9:169-74.

38. Kakel R. Trampoline fracture of the proximal tibial metaphysis in children may not progress into valgus: a report of seven cases and a brief review. Orthop Traumatol Surg Res 2012;98:446-9.

39. Eager DB, Scarrott C, Nixon J, Alexander K. Injury survey of a non-traditional 'soft-edged' trampoline designed to lower equipment hazards. Int J Inj Contr Saf Promot 2013;20:42-9.

40. Ashby K, Eager D, D'Elia A, Day L. Influence of voluntary standards and design modifications on trampoline injury in Victoria, Australia. Inj Prev 2015;21:314-9. 